\title{
PERSPECTIVA DOCENTE E DISCENTE SOBRE AS ATITUDES NAS AULAS DE EDUCAÇÃO FÍSICA: UM ESTUDO DE CASO
}

\author{
Iara Cristina Galharde Carrasco \\ Secretaria de Estado da Educação, Carapicuiba, São Paulo, Brasil \\ Ronê Paiano \\ Universidade Presbiteriana Mackenzie, Barueri, São Paulo, Brasil \\ Elisbete dos Santos Freire \\ Universidade Presbiteriana Mackenzie, Barueri, São Paulo, Brasil
}

\begin{abstract}
Resumo: Este estudo teve como objetivos: analisar a percepção do professor de Educação Física sobre seu trabalho com a dimensão atitudinal e identificar a opinião dos alunos sobre suas atitudes, as atitudes dos colegas e a postura esperada do professor. Entrevistamos um professor de educação física e aplicamos um questionário para 45 alunos de uma escola pública de São Paulo. $\mathrm{O}$ professor demonstrou se preocupar com as atitudes dos seus alunos procurando desenvolver neles iniciativa, respeito, responsabilidade e cooperação. Os alunos acreditam ter uma boa participação em aula baseados nas suas atitudes e no empenho nas aulas. Esperam de seus colegas, respeito, participação, colaboração e seriedade. Quanto ao professor esperam educação, compreensão, diálogo e que puna a indisciplina.
\end{abstract}

Palavras-chave: Educação Física; Valores; Dimensão Atitudinal

\section{Introdução}

Nos últimos anos tem acontecido de forma mais freqüente o debate sobre os conhecimentos que devem ser construídos pelos alunos nas aulas de Educação Física. Nesse debate, um dos aspectos que tem se destacado é a necessidade de que esses conhecimentos sejam significantes e contribuam para que o movimento humano apareça de forma mais consciente e intencional no cotidiano das pessoas. Por isso mesmo, não basta que o aluno aprenda um conjunto de técnicas e procedimentos para a ampliação de seu repertório motor. Aliado a esse "saber fazer", que constitui em parte o conteúdo procedimental da Educação Física, é preciso que se aprenda também conteúdos conceituais que envolvem o conhecimento que aluno deverá aprender sobre o movimento ou sobre a Educação Física (FREIRE; MARIZ DE OLIVEIRA, 2004; BRASIL, 1997).

Nas aulas de Educação Física, assim como em qualquer outra área, a interação social está presente e exige de todos os participantes um comportamento construído com base em determinadas normas. Alunos e professores também tomam atitudes, muitas delas fundamentas 
em seus valores. Normas, atitudes e valores compõem a dimensão atitudinal que, assim como os conteúdos procedimentais e conceituais, faz parte do currículo escolar (BRASIL, 1997; COLL et al, 2000). Nessa medida, esta dimensão deve ser alvo de planejamento por parte do professor, como salientam Martins e Freire (2008) e Freire et al (2010). Contudo, durante muito tempo, esses conteúdos não apareceram de forma explícita nas aulas, fazendo parte de um "currículo oculto" (NICOLETTI, 2003).

Segundo Coll (2000, p.163), o valor é um "princípio normativo que preside e regula o comportamento das pessoas em qualquer momento ou situação". Na visão de Zabala (1998, p. 46), valores são "princípios ou idéias éticas que permitem às pessoas emitir juízos sobre as condutas e seu sentido. São valores: a solidariedade, o respeito aos outros, a responsabilidade, a liberdade, etc.". Na visão de Nicoletti (2003), os valores são mais estáveis do que as atitudes que seriam as manifestações da opinião, tanto verbal quanto gestual

Analisando atitudes e valores, sob as perspectivas acima, podemos concluir que quando um sujeito afirma existir a necessidade de respeitar as diferenças é porque, de certa forma, ele valoriza esta idéia, isto é, carrega em sua vivência esta convicção, possivelmente construída em sua interação familiar (contato primário). Com o convívio social o sujeito administra outras visões através de opiniões que nascem da convicção dos que os rodeiam. Porém, seus valores podem continuar estáveis e internalizados. Quando isto ocorre, sua ação (atitude), seja esta verbal ou gestual, geralmente irá condizer com seus valores.

Ao refletir sobre este simples exemplo podemos considerar então que, o respeito às diferenças, quando carregado como convicção e fazendo parte dos valores de determinada pessoa, lhe permitirá agir de maneira a respeitar, dentre outras coisas, os colegas quanto à etnia, habilidade, sexo e outras características da diversidade, ou seja a atitude.

Sobre as atitudes, Coll et al (2000) afirma que:

Certas atitudes podem evoluir desde estágios de baixa consciência até se transformar em disposições atitudinais, profundamente enraizadas no indivíduo, fruto de reflexão sobre os valores, normas e crença nos quais se apóiam. Há, no entanto, as que serão modificadas ou chegarão inclusive a serem abandonadas, para serem substituídas por outras. Tal aspecto da consistência ou estabilidade atitudinal, é uma questão empírica que o professor deve ter sempre presente e que orientará na hora de analisar as atitudes de cada um de seus alunos, tanto as que são formadas na escola, como aquelas que foram aprendidas basicamente na família (Coll et al, 2000, p. 130).

Assim, os valores são frutos de crenças, da cultura e de convicção intrínseca, os quais permitem ao indivíduo julgar seu comportamento e dos demais. As atitudes, que são ações, se apóiam neles e se diferenciam conforme a personalidade de cada um variando em relação a fatores de conduta, afetivos e cognitivos e que podem ser manifestadas tanto gestualmente quanto verbalmente, perdurando ao longo da vida ou até mesmo sendo substituídas por outras.

$\mathrm{Na}$ Educação Física, embora muito se fale sobre atitudes e valores, temos encontrado poucos estudos sobre a dimensão atitudinal dos conteúdos presentes nas aulas. Um deles foi realizado por Martins e Freire (2008) que analisaram normas, atitudes e valores presentes nas

Pensar a Prática, Goiânia, v. 14, n. 1, p. 1-16, jan./abr. 2011 
aulas de um professor. As autoras verificaram que existem inúmeros conteúdos atitudinais nas aulas, mas nem sempre o professor tem consciência desses conteúdos. Além disso, constataram que o ensino desses conteúdos acontece sem que haja planejamento por parte do professor. Confirmando esse resultado, Nicoletti (2003) afirma que

a importância que a educação física atribui hoje à dimensão atitudinal dos conteúdos oferece um caminho, ainda, pouco explorado de forma explicita e consciente pelos professores. Mesmo que os professores possam desenvolver no seu dia a dia esse conteúdo no chamado currículo oculto, provavelmente, será quase sem saber como (NICOLETTI, 2003, p. 3).

A dimensão atitudinal deve ser trabalhada de maneira intencional não apenas para formar pessoas, mas também para garantir a participação de um número maior de alunos nas aulas, pois, como afirma Paiano (2006, p. 56),

A busca de processos de ensino-aprendizagem eficazes, aliados à atenção que o professor deve ter em relação a esse aspecto, buscando desenvolver nos alunos o respeito por essas diferenças no desempenho, devem ser objetivos primordiais para aqueles que desejam a participação de todos os alunos. (PAIANO, 2006, p. $56)$.

Contudo, para que o professor consiga aplicar uma prática pedagógica, intencionalmente elaborada, que objetive a construção de atitudes e valores nas aulas de Educação Física, é preciso compreender melhor como a dimensão atitudinal dos conteúdos aparece nas aulas. É necessário também que se analise não só a perspectiva de professores sobre os valores e atitudes desejados, mas conhecer também como pensam os alunos sobre esses elementos da dimensão atitudinal.

Dessa forma, o presente estudo teve como objetivos analisar a percepção do professor sobre seu trabalho com a dimensão atitudinal e identificar a opinião dos alunos sobre suas atitudes, atitudes dos colegas e do professor, durante as aulas de educação física.

\section{Método}

Realizamos um estudo descritivo, seguindo abordagem qualitativa, segundo Triviños (1987). Optamos por aplicar um Estudo de Caso, analisando em profundidade uma única realidade. Assim, selecionamos um professor de Educação Física de uma Escola Estadual do município de Carapicuíba. Para selecionar esse professor, inicialmente entramos em contato com os responsáveis pela Delegacia de Ensino da Região e apresentamos o estudo, solicitando autorização para sua realização. Em seguida pedimos sugestões de escolas da região, nas quais houvesse um profissional responsável, compromissado, assíduo e que fosse bem avaliado pela direção e coordenação. Nesse momento foi sugerido o professor estudado.

Além do professor, participaram do estudo 45 estudantes, com idade entre 12 e 18 anos, cursando da $6^{\mathrm{a}}$ série do Ensino Fundamental ao $1^{\mathrm{o}}$ ano do Ensino Médio, sendo 16 meninos e 29 meninas. Os 16 meninos eram 10 de 13 e 14 anos (sujeitos 1 a 10) e 6 de 16, 17 e 18 anos 
(sujeitos 11 a 16). As 29 meninas eram 25 de 12 a 14 anos (sujeitos 17 a41) e 4 de 16 a 18 anos (sujeitos 42 a 45).

Em relação aos procedimentos éticos, o sujeito, a instituição e os responsáveis pelos sujeitos menores de idade envolvidos foram informados sobre o estudo e assinaram o Termo de Consentimento Livre e Esclarecido antes do início da coleta.

Para coleta de dados foi realizada uma entrevista não-estruturada com professor. Em relação aos estudantes, optamos pela aplicação um questionário, após a aula de Educação Física. Nesse questionário foram apresentadas 5 questões abertas, nas quais solicitamos que os alunos explicassem suas percepções sobre suas próprias atitudes, as atitudes de seus colegas e as atitudes do professor.

Para a análise das questões lançamos mão de uma adaptação utilizada por Simões (1994), da Análise de Conteúdo de Bardin (1977). Para Bardin (apud Triviños, 1987, p.161 e 162) existem três etapas fundamentais no trabalho com a análise de conteúdos: a pré-analise, em que consiste na organização de materiais; a discrição analítica, no qual o material coletado está embasado pela hipótese e as referencias teóricas, nesta etapa é comum realizar como procedimento "a codificação, a classificação e a categorização"; e por ultimo a fase de interpretação referencial que é embasado nos materiais já organizados na pré-analise, em que a reflexão e a intuição são fundamentadas nos matérias organizadas, estabelecendo as relações. Em função disto, no primeiro nível de análise foram extraídas 187 unidades de significado. Para cada questão estas unidades foram reunidas em subcategorias no segundo nível de análise e, finalmente, estas subcategorias foram agrupadas em categorias maiores para os comentários no terceiro nível de análise.

\section{Resultados e discussão}

O professor

O sujeito entrevistado tem 37 anos, sexo masculino e ministra aulas de educação física para alunos do ensino fundamental e médio em uma escola pública estadual do município de Carapicuíba, São Paulo. Possui 15 anos de experiência tendo se formado no ano de 1993 pela Universidade de Mogi das Cruzes, no interior de São Paulo. Realizamos a entrevista na sala de materiais de educação física que apesar de pequena nos propiciou a privacidade e tranqüilidade necessárias. Optamos por utilizar o nome fictício de Paulo para identificar as falas do professor.

Iniciando a entrevista, perguntamos ao professor se ele valorizava mais uma das dimensões do conteúdo. Ele respondeu que, para ele, a dimensão atitudinal é a mais importante e que busca, durante as aulas de Educação Física, a participação de todos e a igualdade no relacionamento entre professor e aluno.

Quando perguntado sobre que atitudes espera de seus alunos, ele respondeu esperar várias atitudes e inicialmente citou a "iniciativa" ou pró-atividade. Posteriormente aparecem em seu discurso vários outros conteúdos atitudinais como liderança, direitos, igualdade, discriminação, participação, criatividade, respeito, cooperação e responsabilidade. Podemos identificar alguns desses conteúdos nos trechos da entrevista que destacamos a seguir:

Pensar a Prática, Goiânia, v. 14, n. 1, p. 1-16, jan./abr. 2011 
Paulo- Eu estimulo muito o aluno que é inibido a ser capitão da equipe pra tomar atitudes de liderança. Eu incentivo o aluno que não é preferido da turma, ou seja, que não é o atleta, a tomar uma postura de falar: eu não quero isso nesse momento, eu quero uma outra coisa e a atitude que eu espero é iniciativa.

Paulo - Eu trabalho muito a questão de direitos, igualdade. Nós estamos aqui numa quadra e todos tem direitos. Todos podem fazer. Todos devem fazer. As meninas cobram os mesmos direitos em tempo com os meninos. Enquanto meninas fazem uma atividade meninos vão fazer outra e vice e versa. Então elas cobram cada minuto. Isto é uma atitude de iniciativa que não tem preço. Professor

Dessa forma, podemos verificar que o professor, em seu discurso destaca conteúdos atitudinais transversais, ou seja, que cabem à qualquer componente curricular estimular a construção. Essa parece ser uma tendência entre os professores, pois resultado semelhante foi encontrado por Silva e Freire (2007) e Silva (2007). Martins e Freire (2008) explicam essa tendência ao afirmar que nem sempre o professor percebe os conteúdos atitudinais que ensina. As autoras constataram que, embora os professores citem apenas valores gerais, durante a aplicação das aulas outros conteúdos aparecem, inclusive aqueles que são específicos da Educação Física, ou seja, relacionados à prática motora.

Em seguida, perguntamos ao professor se ele trabalha intencionalmente com os conteúdos atitudinais ou se o trabalho com esses conteúdos acontece espontaneamente. Ele responde que em algumas situações aplica estratégias planejadas previamente. Em outros momentos, o trabalho acontece sem tanto planejamento. Cita exemplos de situações criadas com o objetivo de estimular a reflexão dos alunos e, consequentemente, formar atitudes. Um dos exemplos citados foi a realização da auto-avaliação, para que o aluno seja capaz de avaliar suas próprias atitudes.

Em outro exemplo, o professor explica que uma das propostas de seu trabalho é a participação dos alunos na elaboração e aplicação de eventos esportivos, como aparece no trecho em destaque,

Paulo - No bimestre do voleibol eu coloquei todo mundo pra trabalhar na mesma coisa, ou seja, tinha árbitro, tinha bandeira, tinha mesário...tinha atletas, tinha técnico, preparador físico. Cada um com sua função. As pessoas foram se descobrindo. Então isso foi intencional. Professor

Na descrição apresentada pelo professor podemos identificar uma estratégia importante para estimular a formação de atitudes e valores, que é a atribuição de papéis de responsabilidade. Essa estratégia é defendida por Tillman (2001), que salienta a necessidade de que o aluno possa tomar decisões a assumir as consequiências de seus atos para construir suas atitudes. Sarabia (2000) concorda com Tillman (2001) e propõe também o role-playing como uma forma de fazer com que os alunos se coloquem nos papéis dos outros.

O professor explica também que realiza atividades em que os alunos constroem material alternativo para ser utilizado nas aulas e acredita que dessa forma estimula nos alunos uma atitude criativa para a prática da atividade física. Além disso, em alguns momentos realiza dinâmicas e debates sobre temas transversais, como o multiculturalismo. Essa estratégia também é defendida

Pensar a Prática, Goiânia, v. 14, n. 1, p. 1-16, jan./abr. 2011 
por Tillman (2001) e Sarabia (2000). Identificamos essa estratégia utilizada pelo professor no seguinte trecho da entrevista:

Paulo - Um dia teve uma brincadeira na sala. Onde trabalhamos o multiculturalismo. Busquei enfatizar sobre que a discriminação não leva a nada. Sobre a cor, costume diferente, sexualidade. Perceberam? Somos pessoas! A gente precisa respeitar um ao outro. Professor

Em todas essas estratégias apontadas, é possível perceber que o professor quer estimular nos alunos a internalização de normas, atitudes e valores, levando seus alunos a construir seu comportamento a partir de sua própria reflexão. Sarabia (2000) explica que as atitudes podem ser construídas de três formas: submissão, imitação e internalização, sendo que esta última aparece quando a pessoa é capaz de tomar suas próprias decisões, de forma consciente.

Contudo, embora o professor apresente exemplos de atividades programadas intencionalmente para a construção de atitudes em seus alunos, acrescenta algumas formas que surgiram sem planejamento e que foram copiadas pelos alunos, levando a mudança na atitude deles, como podemos identificar nesse trecho:

Paulo - Levo os coletes que nós usamos pra lavar, ou seja, as primeiras vezes eu levei. Eles falam: "professor deixa-me levar os coletes essa semana pra lavar. Só o senhor lava?”.

Paulo - O aluno sai do jogo ou vai ser o próximo. Pega uma vassoura que eu levo e varre a quadra.

Nesses dois trechos, o professor demonstra estimular os alunos a atitudes de cooperação e co-responsabilidade, não pela imposição mas sim pelo exemplo. Percebemos que as atitudes do professor são imitadas pelo aluno sendo por vezes um modelo para eles. A imitação é outra forma importante de estimular a aprendizagem dos conteúdos atitudinais, como explica Sarabia (2000).

Os alunos e suas atitudes

Na primeira questão perguntamos aos alunos como tem sido as atitudes deles durante as aulas de Educação Física. A maioria deles apresenta uma avaliação positiva sobre seu comportamento. Alguns analisam sua participação, seu desenvolvimento ou aprendizagem, como podemos perceber nos trechos apresentados abaixo:

Sujeito 1 As minhas atitudes tem sido normal. Participo das aulas, gosto muito de educação física e participo de todas as aulas.

Sujeito 23 Eu acho que estou me empenhando aos poucos. Eu não sou muito boa nos esportes em geral. Mais eu estou tentando alcançar os meus objetivos.

Apenas um menino respondeu reconhecendo que às vezes fica nervoso,

Pensar a Prática, Goiânia, v. 14, n. 1, p. 1-16, jan./abr. 2011 
Sujeito 3 As minhas atitudes são muito boa, mas de vez em quando eu dou umas falhas, assim, ser grosso, ficar nervoso, mas não xingar falar palavrão. Somente isso. Nada mais.

Algumas meninas reconheceram não ter atitude adequada sendo uma delas também por nervosismo e as demais por reduzida participação.

Sujeito 20 Eu participo de todas as aulas de educação física. As vezes eu fico meio nervosa. as vezes eu não gosto muito das aulas aí eu não participo mas eu gosto do mesmo jeito.

Sujeito 42 Não muito boa. Faço quando eu posso fazer. É muito bom fazer educação física.

Nas falas acima aparecem aspectos da personalidade de cada um, contudo, percebemos que, de forma geral, os alunos se auto-avaliam a partir de atitudes como participação, aprendizagem, bom relacionamento e controle de suas emoções. Esses aspectos também aparecem na fala do professor, como foi possível perceber na análise da entrevista. Assim, alunos em suas respostas, evidenciam que utilizam os valores do professor para julgar se suas atitudes estão corretas ou incorretas.

Essa influência percebida pode ser uma conseqüência da admiração e do respeito que os alunos parecem ter pelo professor. Essa admiração pode ser notada em diversos momentos dos questionários, inclusive nos trechos abaixo:

Sujeito 11 Nunca na minha vida eu tive educação física igual esse ano, muito boa, o professor é responsável coloca a regra toda hora.

Sujeito $33 \mathrm{Eu}$ aprendo super bem nas aulas. O professor é ótimo e ensina super bem. Eu respeito todos os alunos mas tem vários que não sabem respeitar os outros.

Percebemos então que há uma identificação entre professor e alunos, o que pode fazer com que os alunos procurem imitar o comportamento do professor, como salienta Sarabia (2000), a identificação não é puramente uma imitação, ao contrário, há identificação quando surgem os "laços emocionais e psicológicos" (p. 147). Martins e Freire (2008) também verificaram a presença da identificação como estratégia para que os alunos aprendam atitudes nas aulas de Educação Física. A partir desses resultados, podemos comprovar que os alunos que participaram do estudo estão construindo seus valores e atitudes sobre a Educação Física a partir dos exemplos e referências de seu professor.

Pensar a Prática, Goiânia, v. 14, n. 1, p. 1-16, jan./abr. 2011 
Os alunos e as atitudes dos colegas

Quando perguntados sobre que atitudes esperam de seus colegas, a análise das subcategorias nos permitiu reunir as respostas em duas grandes categorias: atitudes individuais (subcategorias 1 a 5) e conduta em relação às aulas (subcategorias 6 a 10), como mostra o quadro 1

\begin{tabular}{|c|c|c|c|c|c|c|c|c|c|c|c|}
\hline $\begin{array}{l}\mathscr{0} \\
\frac{0}{0} \\
\frac{0}{5} \\
\mathscr{\omega}\end{array}$ & 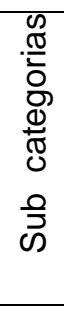 & 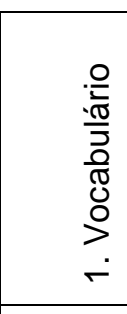 & 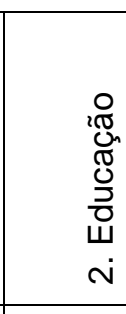 & 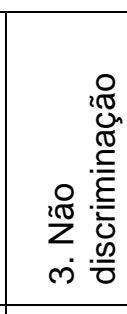 & 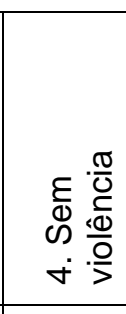 & $\begin{array}{l}\frac{20}{\frac{20}{E}} \\
\frac{5}{5} \\
\text { ம0 }\end{array}$ & 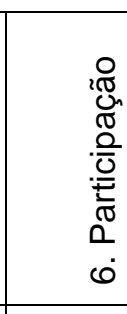 & 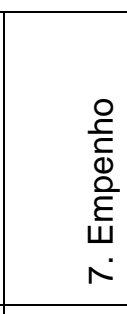 & $\begin{array}{l}\frac{O}{U} \\
\frac{C}{\mathbb{U}} \\
\overline{\bar{C}} \\
\infty\end{array}$ & 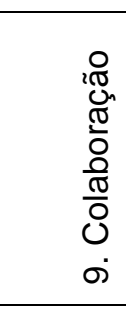 & $\begin{array}{l}\frac{1}{0} \\
\frac{\pi}{0} \\
\frac{d}{0} \\
\frac{0}{0} \\
\oplus \\
0 \\
0\end{array}$ \\
\hline & 1 & $x$ & & & & & & & & $x$ & \\
\hline & 2 & & $x$ & & & & & & & & $x$ \\
\hline & 3 & $x$ & & & $x$ & & & & & & \\
\hline & 4 & & $x$ & & & & $X$ & $x$ & & & $x$ \\
\hline & 5 & & & & & & & & & $x$ & \\
\hline & 6 & & $X$ & & & & & $x$ & & & \\
\hline & 7 & & & $x$ & & & & & & & \\
\hline & 8 & $x$ & $x$ & & & & & & $x$ & & \\
\hline & 9 & & & & & $x$ & & & & & \\
\hline & 10 & & & & $x$ & & & & & & \\
\hline & 11 & & & & & $x$ & & & & & \\
\hline & 12 & & $x$ & & $x$ & $x$ & & & & & \\
\hline & 13 & & & & & & $X$ & & & & \\
\hline & 14 & & $x$ & & & & $x$ & & & & \\
\hline & 15 & & & & & & $x$ & $x$ & & & \\
\hline & 16 & & $X$ & & & & $x$ & & $x$ & & \\
\hline & 17 & & & & $x$ & & & & & & $x$ \\
\hline & 18 & & & & $x$ & & & & & & \\
\hline & 19 & & & & & & & & $x$ & & \\
\hline & 20 & & & & $x$ & & & & & $x$ & $x$ \\
\hline & 21 & & & & & & $X$ & & & $x$ & \\
\hline & 22 & & & & & & & $x$ & & & \\
\hline & 23 & & $X$ & & & & & $x$ & & & \\
\hline & 24 & & $X$ & & & & & & & & \\
\hline & 25 & & & & & & $X$ & & & & $x$ \\
\hline & 26 & & & & & & & & $X$ & & $x$ \\
\hline & 27 & & $X$ & & & $X$ & & & & & $x$ \\
\hline
\end{tabular}

Pensar a Prática, Goiânia, v. 14, n. 1, p. 1-16, jan./abr. 2011 


\begin{tabular}{|c|c|c|c|c|c|c|c|c|c|}
\hline 28 & & & & & & & & $X$ & \\
\hline 29 & & $X$ & & & & & $X$ & & \\
\hline 30 & & & $X$ & & & & $x$ & & \\
\hline 31 & & $X$ & & & & & $X$ & & \\
\hline 32 & & & & & & & $X$ & & \\
\hline 33 & & $X$ & & & & & & & \\
\hline 34 & & $X$ & & & & & & $X$ & $x$ \\
\hline 35 & & $X$ & & & & & & $X$ & $X$ \\
\hline 36 & & $X$ & & & & & & $X$ & $X$ \\
\hline 37 & & $X$ & & & & $X$ & & & $X$ \\
\hline 38 & & $X$ & & & & $X$ & & & $x$ \\
\hline 39 & $X$ & & & $X$ & & & & $X$ & \\
\hline 40 & & & & & & & & & \\
\hline 41 & & $X$ & & & & & & & \\
\hline 42 & & $X$ & & & & $X$ & $X$ & & \\
\hline 43 & & & & $X$ & $x$ & & & & \\
\hline 44 & & & & & $x$ & & & & $x$ \\
\hline 45 & & & & $X$ & $X$ & $X$ & & & \\
\hline
\end{tabular}

Quadro 1 Atitudes esperadas em relação aos colegas.

É interessante verificar que os sujeitos desse estudo, quando perguntados sobre que atitudes esperam de seus colegas, a resposta que aparece com maior freqüência é a educação. Quando isto não ocorre os alunos podem se distanciar das aulas. Neste mesmo sentido Paiano (2006, p. 56) comprovou em seu trabalho que "o desrespeito, as humilhações e as gozações a que este grupo de alunos menos habilidosos é submetido na educação física, surgiram como principal fator para sua "fuga" das aulas."

Nessa medida, alguns alunos são bastante críticos em relação aos colegas como podemos observar nos trechos apresentados a seguir:

Sujeito $2 \mathrm{Eu}$ espero uma atitude boa como respeitar o professor prestar atenção e não ficar com brincadeira na aula

Sujeito 8 Que eles melhorem e que parem de falar principalmente palavrões.

Sujeito 34 Que eles respeitem a aula do professor e que colaborem para que a nossa aula possa ser muito mais aproveitada

Shigunov e Pereira (1994), lembram a importância de cuidar do seu vocabulário e dos alunos. Eles frisam a necessidade de aplicação de atitudes "como, por favor, obrigado e desculpe que o professor pode empregar para que vários objetivos sejam conquistados em suas aulas"(SHIGUNOV e PEREIRA, 1994, p. 44-45).

Pensar a Prática, Goiânia, v. 14, n. 1, p. 1-16, jan./abr. 2011 
Nesta categoria aparece também o desejo de que seus colegas tomem cuidado quanto ao vocabulário, discriminação, violência e união.

Quando analisamos a outra categoria, que diz respeito às atitudes esperadas em relação às aulas, é interessante perceber que a maioria dos alunos cobra a seriedade dos colegas na aula de educação física, além de: participação, empenho, colaboração e silêncio. Nestes itens percebemos que não aparece desempenho ou habilidade, que para serem atingidos demandariam mais tempo. Logo, o que os alunos esperam de seus colegas é algo que está ao alcance de todos, suas atitudes.

Devemos lembrar que "seriedade", por incrível que pareça, é um objetivo que nós, profissionais de educação física, buscamos para o reconhecimento de nossa importância no mercado de trabalho. Pelos resultados em questão, este grupo de alunos também espera esta seriedade dos colegas nas aulas. Os depoimentos abaixo sinalizam esta vontade dos alunos:

Sujeito 4: "Atitude de respeito com os outros alunos e levar a educação física a sério."

Sujeito 27: "Educação, humildade, colega. Espero que sejam legais, educados e amigos".

Sujeito 44: "Melhores que estão agora e pensar um pouco mais".

Se este grupo de alunos se posiciona verbalmente de forma mais crítica, conseqüentemente exigirão do professor novas competências.

Os alunos desta pesquisa estão sinalizando a necessidade de mudanças na educação física, especialmente em relação aos cuidados com a dimensão atitudinal, o que é positivo, pois podemos utilizar destas visões em nosso diagnóstico, avaliação, auto-avaliação e execução de um novo planejamento se necessário.

Os alunos e as atitudes do professor

As manifestações dos alunos sobre as atitudes que esperam do professor foram reunidas em nove sub-categorias e aparecem no quadro 2.

Pensar a Prática, Goiânia, v. 14, n. 1, p. 1-16, jan./abr. 2011 


\begin{tabular}{|c|c|c|c|c|c|c|c|c|c|}
\hline 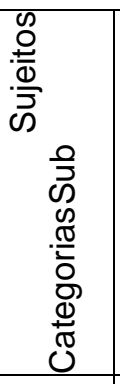 & 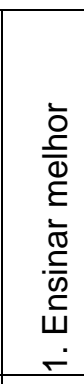 & 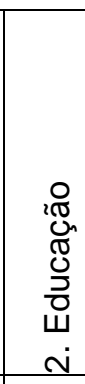 & 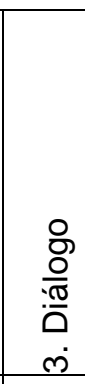 & 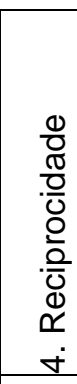 & 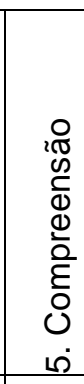 & 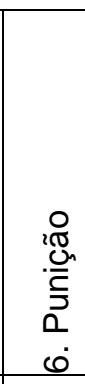 & 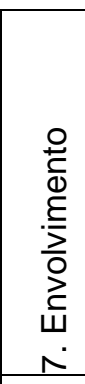 & 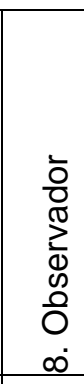 & 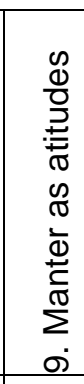 \\
\hline 1 & $X$ & & & & & & & & $x$ \\
\hline 2 & & & & & & & & $X$ & $X$ \\
\hline 3 & & & & & & $X$ & & & $X$ \\
\hline 4 & & & & $x$ & $X$ & & & & $x$ \\
\hline 5 & $X$ & $x$ & & & & & & & $X$ \\
\hline 6 & $x$ & & & & & & & & \\
\hline 7 & & & & & & $x$ & & & \\
\hline 8 & & & & & & $x$ & & $X$ & \\
\hline 9 & & & & & & $x$ & & & $X$ \\
\hline 10 & $x$ & & $X$ & & & & & & \\
\hline 11 & & & & & $x$ & & & & \\
\hline 12 & & & $x$ & & & $x$ & & $x$ & \\
\hline 13 & & & & & & $x$ & $X$ & & \\
\hline 14 & $x$ & & & & & & & & \\
\hline 15 & & $x$ & & & $x$ & & & & \\
\hline 16 & & & & & & & & & $X$ \\
\hline 17 & & $x$ & & & & & & & $x$ \\
\hline 18 & & $x$ & & & & $x$ & & & \\
\hline 19 & & & & $x$ & & & & & $x$ \\
\hline 20 & & & & & & $x$ & & $x$ & \\
\hline 21 & & & & & & $x$ & & $x$ & \\
\hline 22 & & & & & $x$ & & & & $X$ \\
\hline 23 & & $x$ & & & & $x$ & & & \\
\hline 24 & $x$ & & & $x$ & & & & & \\
\hline 25 & $x$ & $x$ & $x$ & & & $x$ & & & \\
\hline 26 & & & $X$ & $X$ & $X$ & & & & $X$ \\
\hline 27 & $x$ & $x$ & $x$ & $x$ & $x$ & & $X$ & & \\
\hline 28 & $x$ & & & $x$ & & & $X$ & & $x$ \\
\hline 29 & & & & & $x$ & & & & $x$ \\
\hline 30 & & & $x$ & & & $x$ & & & $x$ \\
\hline 31 & & & & $x$ & $x$ & $x$ & & & $x$ \\
\hline
\end{tabular}

Pensar a Prática, Goiânia, v. 14, n. 1, p. 1-16, jan./abr. 2011 


\begin{tabular}{|c|c|c|c|c|c|c|c|c|}
\hline 32 & & & $X$ & & & & & $x$ \\
\hline 33 & $X$ & & & & $x$ & & & \\
\hline 34 & & & $X$ & $X$ & $x$ & $X$ & & $X$ \\
\hline 35 & & & $x$ & & $x$ & $x$ & & \\
\hline 36 & & & & $X$ & $x$ & $x$ & & \\
\hline 37 & & $X$ & $X$ & & & $X$ & & \\
\hline 38 & & & $x$ & & & & & $X$ \\
\hline 39 & & & & & $x$ & & & $x$ \\
\hline 40 & & & & & $x$ & & & \\
\hline 41 & & & & & & & $X$ & \\
\hline 42 & & & & $X$ & $x$ & & & \\
\hline 43 & & & & $X$ & & & & $X$ \\
\hline 44 & $X$ & & & & & & & \\
\hline 45 & & & & & & & & $X$ \\
\hline
\end{tabular}

Quadro 2 Atitudes esperadas do professor

A análise do quadro nos permite verificar que parte deste grupo de alunos quer um professor com educação, diálogo, reciprocidade, compreensão e envolvimento, respectivamente as subcategorias 2,3,4,5 e7.

Quando perguntamos aos alunos que atitudes esperam do professor, grande parte se declara satisfeita e que deseja que ele continue atuando da mesma forma (subcategoria 9), por outro lado, há também um elevado número de alunos que espera que o professor seja mais observador e rígido, punindo alunos que apresentem um comportamento impróprio (subcategorias 6 e 8). Esses dados evidenciam um conflito na opinião dos alunos o que pode demonstrar que apesar do apoio de parte dos alunos à postura do professor e de toda a preocupação dele com a dimensão atitudinal, é possível, que o comportamento inadequado apareça de forma freqüente nas aulas. Como salienta Paiano (2006), atitudes inadequadas potencializam a não participação.

É possível também que o professor, em nome de uma valorização do dialogo e temendo adotar atitudes autoritárias, desconsidere a necessidade de punição ou de alguma implicação para o caso do descumprimento das normas estabelecidas. Como foi possível perceber na entrevista, a valorização da conversa e a proposta de evitar o autoritarismo aparece em seu discurso.

É possível ainda que os alunos que cobram maior punição atribuam ao professor o papel de autoridade e que esperem dele um maior controle do comportamento dos colegas durante as aulas. Em seu discurso, os estudantes parecem defender posições autoritárias em aula, talvez porque tenham inúmeros exemplos de autoritarismo em seu cotidiano.

No entanto, reconhecendo as limitações do presente estudo não é possível afirmar qual dessas possibilidades é real. Para isso é necessário que novas pesquisas sejam realizadas, pesquisas essas que, além de analisar os discursos dos sujeitos utilize também da observação de aulas, coletando dados sobre as relações estabelecidas no cotidiano escolar.

O que se pode afirmar, com certeza, é que os alunos refletem sobre as atitudes dos colegas e possuem inúmeras expectativas sobre essas atitudes e também sobre as atitudes do

Pensar a Prática, Goiânia, v. 14, n. 1, p. 1-16, jan./abr. 2011 
professor. Desta forma, se evidencia a existência de um ambiente que pode ser bem utilizado pelo professor para construir atitudes, utilizando estratégias que levem à sua internalização. Estimular ainda mais essa reflexão, abrindo espaço para debater as expectativas dos alunos pode ser uma estratégia adequada para viabilizar essa internalização (SARABIA, 2000).

Interessante seria que, a partir desse debate, os próprios estudantes construíssem as regras de comportamento a serem adotadas e as possíveis conseqüências que sofreriam aqueles que as descumprissem. Contudo, é preciso ressaltar que o professor tem papel fundamental ao envolver os alunos na construção dos chamados "combinados". Nesse momento ele não pode atuar como um observador, que apenas acata as decisões de sua turma. Ele também deve participar das regras, definido alguns limites para que não se perca o objetivo das aulas de Educação Física e para garantir a segurança física e moral de seus alunos. Além disso, definidas as regras, ele mantém o papel de autoridade e deve ser responsável pelo cumprimento dessas normas.

\section{Conclusão}

Iniciamos esse estudo de caso com os objetivos de analisar a percepção do professor sobre seu trabalho com a dimensão atitudinal e identificar a opinião dos alunos sobre suas atitudes, as atitudes de seus colegas e que postura esperam do professor. De forma geral, foi possível perceber, pela grande quantidade de unidades de significado presentes nas subcategorias e posteriormente agrupadas em categorias, que a dimensão atitudinal é algo extremamente importante e presente no universo escolar de alunos e professores.

Percebemos no discurso do professor uma grande preocupação com a formação das atitudes de seus alunos e a construção de estratégias para a internalização de conteúdos como participação, iniciativa, respeito, responsabilidade e cooperação. É importante que novos estudos sejam realizados para que se possa verificar se esses valores preconizados pelo professor aparecem também na intervenção de outros docentes e quais outros valores podem ser vistos.

Nos questionários aplicados aos alunos foi possível verificar que esses conteúdos também estão presentes e muitos deles assumem como seus os valores do professor. Os alunos, de uma forma geral, acreditam ter uma boa participação em aula. Utilizam como parâmetros para esta análise as atitudes e o empenho nas aulas. Esperam dos colegas um comportamento que valorize o respeito, a igualdade, a não violência e a união. Além disso, querem também participação, empenho, silêncio, colaboração e seriedade. Percebemos também que os alunos desejam um professor educado, compreensivo, aberto ao diálogo, mas, ao mesmo tempo, uma grande parte espera que ele observe e puna os alunos que tomam atitudes consideradas indevidas, demonstrando que eles não toleram a impunidade.

Constatamos a presença de muitas expectativas dos alunos quanto às suas atitudes e às atitudes dos colegas e do professor, demonstrando que, no caso investigado, os alunos refletem sobre conteúdos atitudinais presentes nas aulas de Educação Física e que as atitudes de todos são problemas significantes para eles. Talvez, esta seja uma conseqüência do trabalho realizado pelo professor escolhido para o estudo. Novos estudos devem ser realizados para que possamos verificar se essas expectativas se repetem em outros casos.

Pensar a Prática, Goiânia, v. 14, n. 1, p. 1-16, jan./abr. 2011 
Os dados obtidos permitem afirmar a importância de que o professor procure identificar as expectativas de seus alunos com relação às atitudes. É preciso também que ele entenda a presença desses problemas como momento especial, permitindo o envolvimento dos alunos na construção das regras de convivência. Esse envolvimento é um estímulo para que eles vivenciem valores e atitudes que, se internalizados serão adotados não apenas durante as aulas de Educação Física, o que nem sempre acontece quando se utiliza da submissão ou da identificação.

A nossa sociedade necessita que todos os que atuam na área de educação colaborem para melhorar a qualidade do relacionamento humano, diminuindo a intolerância, a violência, o desrespeito e conscientizando os alunos da importância da educação e da reciprocidade, ou seja, respeitar para ser respeitado. Estas atitudes de grande relevância justificam a necessidade de uma abordagem mais humana e significativa da qual a educação física não apenas não pode se eximir, como é elemento indispensável na formação atitudinal dos alunos.

\section{Referências}

BARDIN, L. Análise de conteúdo. Lisboa: Edições 70, 1977.

BRASIL MEC. Secretaria de Ensino Fundamental. Parâmetros curriculares nacionais: Educação Física. Brasília: MEC/SEF, 1997.

COLL, César et al; Os conteúdos na reforma: Ensino e aprendizagem de conceitos, procedimentos e atitudes: Porto Alegre: Artmed, 2000.

GUIMARÃES, Ana Archangelo et al. Educação Física Escolar: Atitudes e Valores. Revista

Motriz, Rio Claro, v.7, n.1, pp.17-22, jan/jun. 2001. Disponível em : http://www.rc.unesp.br/ib/efísica/motriz/07n1/guimarães.pdf. Acesso em 09.Mar.2007.

MARTINS, Claudiane Dias; FREIRE, Elisabete dos Santos. Educação física escolar e a dimensão atitudinal do conteúdo: estratégias de ensino utilizadas pelos professores. Seminário de Educação Física Escolar, IX, 2007, Escola de Educação Física e Esporte da Universidade de São Paulo. Anais. São Paulo, 2008.

NICOLETTI, Lucas Portilho. Educação Física e a dimensão Atitudinal: Um estudo de caso. Rio Claro. 2003. Dissertação de Mestrado. Instituto de Biociências. Universidade Estadual Paulista.

PAIANO, Ronê. Possibilidades de orientação da prática pedagógica do Professor de Educação Física: Situações de desprazer na opinião dos alunos. Revista Mackenzie de Educação Física e Esporte, São Paulo, v.5, n.1,p. 47-58,2006.

SANTOS, Ruth dos; FREIRE, Elisabete dos Santos. Educação Física e o Esporte no Terceiro Setor: Estratégias utilizadas no ensino e aprendizagem de valores, atitudes e normas no projeto

Pensar a Prática, Goiânia, v. 14, n. 1, p. 1-16, jan./abr. 2011 
esporte talento. Revista Mackenzie de Educação Física e Esporte, São Paulo, v.5,n.1, p.3545,2006 .

SARABIA, Barnabé. O Aprendizado e o Ensino das Atitudes. In: COLL e Colaboradores. Os conteúdos na reforma. Porto Alegre: Artes Médicas, 2000. p.119-177.

SHIGUNOV,Victor; PEREIRA, Vanildo Rodrigues. Pedagogia da Educação Física: O desporto Coletivo na Escola: São Paulo. p.39-59, IBRASA - SP, 1994.

SILVA, Adriana Ribeiro da; FREIRE, Elisabete dos Santos. A educação física escolar e a dimensão atitudinal: conteúdos selecionados e estratégias de ensino utilizadas pelos professores. Revista Motriz, Rio Claro, v.3, n.2, 2007. p.S311-S32.

SILVA, Kátia Almeida. A dimensão atitudinal nas aulas de educação física: conteúdos e metodologias presentes nos 4 anos iniciais do ensino fundamental. Trabalho. de Graduação Interdisciplinar (Graduação em Educação Física) Universidade Presbiteriana Mackenzie, São Paulo, 2007.

SIMÕES, Regina. Corporeidade e terceira idade: a marginalização do corpo do idoso. Piracicaba: UNIMEP, 1994

TILLMAN, D. Atividades com valores para estudantes de 7 a 14 anos. São Paulo: Editora Confluência, 2001.

TRIVINOS, Augusto Nilbado Silva. Introdução à Pesquisa em Ciências Sociais: A pesquisa qualitativa em educação: São Paulo: Atlas, 1987.

ZABALA, Antoni. A prática educativa: Como ensinar. Porto Alegre: Artmed, 1998.

\title{
PERSPECTIVE ON TEACHERS AND STUDENTS ON THE ATTITUDES OF PHYSICAL EDUCATION IN SCHOOLS: A CASE STUDY
}

\begin{abstract}
This study aimed to: examine the perception of the physical education teacher about his work with the attitudinal dimension and identify the students' opinions about their attitudes, the attitudes of colleagues and the attitude expected of the teacher. We interviewed a professor of physical education and applied a questionnaire to 45 students at a public school in São Paulo. The teacher demonstrated to worry about the attitudes of students looking to develop in them the initiative, respect, responsibility and cooperation. Students believe they have a good class participation based on their attitudes and commitment in the classroom. Expect from their colleagues, respect, participation, collaboration and commitment. As the teacher expect education, understanding, dialogue and to punish indiscipline.
\end{abstract}

Pensar a Prática, Goiânia, v. 14, n. 1, p. 1-16, jan./abr. 2011 
Keywords: Physical Education. Values. Attitudinal Dimension.

\section{PERSPECTIVA DEL DOCENTE Y DE LOS DISCENTES EN LAS ACTITUDES EN LAS LECCIONES DE LA EDUCACIÓN FÍSICA: UN ESTUDIO DE CASO}

Resumen: Este estudio tuvo como objetivo: analizar la percepción del maestro de educación física sobre su trabajo con la dimensión actitudinal y determinar las opiniones de los estudiantes acerca de sus actitudes, las actitudes de los colegas y espera que la actitud del profesor. Entrevistamos a un profesor de educación física y aplicó un cuestionario a 45 estudiantes de una escuela pública de São Paulo. El profesor mostró preocuparse por las actitudes de los estudiantes que buscan desarrollar en ellos la iniciativa, respeto, responsabilidad y cooperación. Los estudiantes creen que tienen una buena participación en clase sobre la base de sus actitudes y el compromiso en el aula. Esperar de sus colegas, respeto, participación, colaboración y compromiso. Como el profesor esperar que la educación, la comprensión, el diálogo y para castigar la indisciplina.

Palabras claves: Educación Física; Valores; Dimensión Actitudinal

Endereço para correspondência:

Iara Cristina Galharde Carrasco

iara.galharde@hotmail.com

Secretaria de Estado da Educação

Diretoria de Ensino - Região de Carapicuiba.

Rua Campo Grande, 181, Cohab II

06328-080 - Carapicuiba, SP - Brasil

Pensar a Prática, Goiânia, v. 14, n. 1, p. 1-16, jan./abr. 2011 